\title{
Methods for Cleaning \& Sanitizing Food Contact Surfaces (Countertops) to Prevent Cross Contamination in Restaurant Kitchens
}

\author{
Laura Matthewson ${ }^{1}$, Helen Heacock ${ }^{2}$ \\ 1 Lead author, B. Tech Student, School of Health Sciences, British Columbia Institute of Technology, 3709 Willingdon Ave, Burnaby, BC V5G 3H2 \\ 2 Supervisor, School of Health Sciences, British Columbia Institute of Technology, 3709 Willingdon Ave, Burnaby, BC V5G 3H2
}

\begin{abstract}
Background: Cross contamination can occur in restaurant kitchens when food contact surfaces such as countertops are inadequately cleaned between preparation of raw and ready to eat foods. Previous research has demonstrated that washing with detergent and water, rinsing, then applying a sanitizer solution is the most effective cleaning method. The second most effective cleaning method is to use detergent and water alone. In practice, the author has observed kitchen staff using sanitizer alone to clean kitchen countertops. This study surveyed British Columbia restaurant kitchen staff on current practices and makes recommendations to improve cleaning and sanitization practices for the purpose of preventing cross contamination.

Methods: A survey was prepared using SurveyMonkey and distributed through Facebook to the author's contacts in the restaurant industry. The Facebook post included a request for anyone to share the survey link with their contacts who work in BC restaurant kitchens. The survey was shared 21 times by 14 different people. The survey asked questions about restaurant type and position, Foodsafe level, and about cleaning practices such as frequency and cleaning compounds used.

Results: When asked what cleaning compounds are most often used to clean work surfaces (countertops) in their restaurant, 56.5\% of respondents reported sanitizer solution only, 30.4\% of respondents reported soap \& water followed by sanitizer solution, and $13.0 \%$ reported soap and water only. When asked why sanitizer solution only was used to clean countertops, $46.2 \%$ of respondents said it was company policy, $23.1 \%$ of respondents said time savings, and $15.4 \%$ of respondents indicated that an Environmental Health Officer had recommended sanitizer use and that is what lead to sanitizer alone being used to clean countertops.

Conclusions: In practice, some restaurant staff do not use sanitizer effectively and may believe it is a substitute for detergent. Using sanitizer alone is not as effective as using detergent alone. Detergent alone can provide a 2-3 log bacterial reduction. If staff are busy and are only going to use one cleaning step, detergent alone is the best method. Environmental Health Officers should review sanitation plans and talk with operators to determine current cleaning practices in food service establishments. Operators and staff should be re-educated on the importance of the three-step method. It may be beneficial to recommend that sanitizer use be decreased overall to encourage the use of soap and water. It may only be necessary to use sanitizer after high-risk jobs such as preparing raw meat or at the end of the day.
\end{abstract}

Keywords: sanitizer, sanitize, sanitizing, disinfect, chemical, effectiveness, efficacy, detergent, soap, food contact surface, countertop, public health, cross contamination, restaurant, food service establishment, dirt, soil, debris, residue, clean 


\section{Introduction}

It is estimated that food borne illness affects 1 in 8 Canadians every year. (1) These illnesses can be severe with some leading to death. Canadians can contract a food borne illness in their own home or while dining out at a restaurant. Food borne illness is a preventable disease if food is prepared and served in a manner that prevents contamination and growth of pathogens. One pathway for microorganisms to enter a food is by cross contamination. Cross contamination can occur when microorganisms from raw food ingredients are unintentionally transferred to ready to eat foods. This can happen when knifes/tools, cutting boards, hands, or countertops are inadequately cleaned and sanitized between jobs. Most guidelines require that food contact surfaces go through a three-step cleaning process: wash, rinse and sanitize. This process should result in a surface that is free from contamination.

Through observation of kitchen staff cleaning countertops, the author has noticed that the three-step method does not always take place. Anecdotally, cooks have told the author that only the sanitizing step (without prior washing and rinsing) is used on dirty countertops throughout the day and in between jobs. In some kitchens, cloths are kept soaking in a bleach solution and periodically used to wipe down dirty surfaces. Alternatively, sanitizer could be sprayed from a bottle onto a dirty surface and wiped off with a towel. Most kitchens are a busy place and cooks may not want to take the time to perform three steps. However, skipping the first two steps could be problematic because sanitizer may not be as effective if applied directly onto a dirty surface

The purpose of the evidence review was to compare the efficacy of using sanitizer alone to detergent alone to detergent followed by a sanitizer. Regulations, guidelines, and studies pertaining to cross contamination and the cleaning \& sanitizing of food contact surfaces were examined. This information was compared with results from a survey of current cleaning practices in British Columbia (BC) restaurant kitchens. This study aims to identify gaps in research, policy and knowledge to direct further action with the intent of improving public health.

\section{Evidence Review \\ Cross Contamination}

Cross contamination can transfer

pathogenic bacteria from raw products to ready to eat foods via cutting boards, utensils, equipment, cleaning cloths and countertops. In many cases, washing or disinfection of kitchen equipment may not be sufficient to remove pathogens. (2) For this reason, it is often recommended that separate utensils and cutting boards be used for raw and ready to eat products. This would not necessarily be practical for certain types of equipment and countertops because they are stationary. Although it is recommended that separate areas of the kitchen be allocated for raw and ready to eat foods, restaurant kitchens are often small and counter space must be used for both jobs. In 1994, Humphrey, Martin, \& Whitehead found that Salmonella enteritidis could be found on surfaces up to $40 \mathrm{~cm}$ away from the mixing bowl after mixing raw eggs and could be recovered up to 24 hours after contamination. (3) This supports the need for effective cleaning and sanitizing of counter tops. It is also important to note that some pathogens have a very low infective dose ( $<100 \mathrm{cfu}$ for E. coli) and if even only a small amount is transferred, it could potentially lead to outbreaks. (4)

\section{Regulations}

Restaurants in $\mathrm{BC}$ are governed under the Food Premises Act and Regulations. (5) Section 17 (1) of the regulations states that "every operator of food premises must ensure that the equipment, utensils and food contact surfaces used on the premises are washed and sanitized in a manner that removes contamination". How this requirement is met is up to the Environmental Health Officer (EHO) and the operator to decide.

Guidance on specific cleaning steps that may be used to meet requirements of the regulations can be found in the Canadian Food Retail and Food Services Code. (6) The code states that cleaning should involve four steps: removing gross debris from surfaces, applying a detergent solution to loosen soil and bacterial film and hold them in solution and suspension, rinse with water to remove loosened soil and residues of detergent, and finally sanitizing.

A general definition of sanitation is the creation and maintenance of hygienic and healthful conditions, and more specifically preventing contamination with 
microorganisms that cause foodborne illness. (7) A more specific definition can be found in the Canadian Food Retail and Food Services Code: "surfaces are effectively sanitized when after application (of a chemical sanitizer) on a cleaned surface, a 5 log reduction of disease causing microorganisms is achieved." (6) The United States Food and Drug Administration (FDA) Food Code states sanitizers must be applied after cleaning and that contact times should be consistent with Environmental Protection Agency registered label use instructions. (8) The contact time for most sanitizing solutions according to the FDA Food Code is 30 seconds.

Health Canada has somewhat different performance standards for non-halide chemical sanitizers. To approve a sanitizer for use, Health Canada requires a 5 log reduction for each bacterium (only specific bacteria that are tested) within a 30 second contact time (likely in a laboratory setting). (9) However, Health Canada also indicates that at specific concentrations of certain sanitizers, 10 minutes contact time is required for sanitization, and in this case they do not mention surface cleanliness. Table 1 lists some Health Canada approved chemical sanitizers.

Table 1. Health Canada Approved Hard Surface Sanitizers (10)

\begin{tabular}{|ll|l|}
\hline $\begin{array}{l}\text { Active } \\
\text { Ingredient }\end{array}$ & $\begin{array}{l}\text { Minimum } \\
\text { Concentration }\end{array}$ & $\begin{array}{l}\text { Contact } \\
\text { time for } \\
\text { Sanitization }\end{array}$ \\
\hline $\begin{array}{l}\text { Quaternary } \\
\text { ammonium } \\
\text { compound }\end{array}$ & $450 \mathrm{ppm}$ & 10 minutes \\
\hline $\begin{array}{l}\text { Chlorine } \\
\text { releasing } \\
\text { compound } \\
\text { e.g. sodium } \\
\text { hypochlorite }\end{array}$ & $100 \mathrm{ppm}$ & 10 minutes \\
\hline
\end{tabular}

It is interesting to note that the both the Canadian Food Retail and Food Services Code and FDA Food Coda require a clean surface and a contact time of 30 seconds whereas Health Canada does not mention surface cleanliness and requires 10 minutes of contact time for sanitization. This could indicate that if restaurant do not use soap and water before sanitizer application, a full 10 minutes of contact time may be required.

Interaction with Organic Matter

A clean surface is required before sanitizing because organic matter decreases the effectiveness of sanitizers. In 2007, Lee, Cartwright, Grueser, \& Pascall found that organic matter protected bacteria in a dishwasher. (11) Although the conditions in a dishwasher are not the same as on a countertop, a similar protective effect could occur. NCCEH also advises that for sanitizers to be effective, the surface must be properly cleansed and rinsed first. (12) A textbook definition states "the function of soap or detergent is to lower the surface tension of water so that soils may be dislodged, loosened, and suspended in solution before rinsing". (7) "Chemical sanitizers do not function to loosen or remove soil and can in fact react with organic materials that have not been previously removed". (7)

Different sanitizers can react differently with organic matter. Two of the most common sanitizers used on countertops contain chlorine or quaternary ammonium compounds as the active ingredient.

Chlorine compounds will react with organic matter and deteriorate rapidly with exposure to light. Quaternary ammonium compounds are said to be more stable when exposed to organic matter but are incompatible when used with soap because of a reaction between cationic and anionic molecules. Detergent and sanitizer cannot be combined into one single step.(7) Bacteria can also be transferred from one surface to another by cleaning cloths themselves.(13) The author has noticed that some restaurants require cloths to be held in a bucket with a chlorine bleach solution, and are then reused throughout the day. This practice can be a problem because of the exposure to light and organic compounds Cloths should be frequently changed throughout the day or disinfected after each use. (13) The best practice would be to use disposable paper towel for cleaning food surfaces and equipment, but this would be wasteful.

\section{Detergent Alone vs. Sanitizer Alone vs. Detergent-Rinse-Sanitize}

The following section compares the effectiveness of using detergent alone to using sanitizer alone to using the recommended method of detergent, rinsing and sanitizing.

In the studies that compared detergentrinse-sanitize (DRS) to soap alone or sanitizer alone, DRS was found to be the most effective, most of the time.(12,14-18) 
DRS was often found to be totally effective for removal of bacteria from various settings while detergent alone was only somewhat effective. (16-18) These studies were executed in a laboratory and factory environment. Since there is some scientific backing to the detergent-rinse-sanitize method, it would be expected to be most effective every time. However, in 1984, Tebutt found that in practice, DRS was less effective than using detergent alone. (13) Tebutt suggested that the frequency and efficacy of cleaning of equipment and work surfaces was more important than use of disinfectant. Tebutt's study involved sampling and conducting a survey regarding cleaning practices at various food premises. In practice, use of disinfectants can lead to a false sense of safety. Staff may believe that the disinfectant can reduce or eliminate the need to use detergent and water. Staff may also not be trained on proper concentration and contact time leading to ineffective use. NCCEH also reported that although a disinfectant is required, regular and effective cleaning might be more important because cleaning and rinsing alone may achieve a 2 to 3 log reduction. (12)

Although Tebutt's study is dated (1984) the inadequate training of staff can still exist in restaurant kitchens today.

In the four studies that compared detergent alone to sanitizer alone, detergent alone was always more effective. $(2,13,14,19)$ In a study by NSF involving dishwashers, a wash cycle using detergent was compared to a sanitizing rinse. Glasses contaminated with E. coli and skim milk were run through an automatic dishwasher. No bacteria were found on the glasses after the detergent wash alone. After just the sanitizing rinse, bacterial counts of $10^{3}$ to $10^{5}$ were found. (19) Although this study involved dishwashers and not countertops and the wash cycle could have imparted more mechanical action than the rinse, the results are still quite significant. In another study involving cutting boards, detergent alone was found to be effective at removing bacterial contamination. (20)

\section{Methods}

The survey was made available online through the Survey Monkey website. (21) A computer was required for the researcher as well as for the respondents to the survey. The researcher posted a link on Facebook and distributed it to her contacts in the restaurant industry. The link connected to the Survey Monkey website where potential respondents read a cover letter detailing purpose and ethical considerations. Potential respondents then decided if they wanted to participate in the survey. The Facebook post included a request for anyone to pass the link along to their contacts who work in BC restaurant kitchens. Ideally this would initiate a "snowball effect" and result in a larger number of responses. The survey was shared 21 times by 14 different people on Facebook. The persons that shared the survey were all "Facebook friends" of the researcher. Although the survey was shared a relatively high number of times, the "snowball effect" did not appear to take place. The Facebook link was left open for 3 weeks and reminders to complete the survey were sent out periodically. All persons who worked in a restaurant kitchen in $\mathrm{BC}$ within the last year were eligible to take the survey. Initially the survey received 47 responses but 24 had to be eliminated for not meeting the inclusion criteria. Respondents were excluded for the following reasons:

1. Answering "no" to the first question:

"Have you worked in a restaurant kitchen in $\mathrm{BC}$ for at least 1 month within the last year and do you agree to participate in the survey?" (7 respondents)

2. Choosing "other" and writing "server" in response to the question: "What is your position in the restaurant kitchen?" (5 respondents)

3. Incomplete responses. (12 respondents) *Note: one respondent who completed all questions but the last one was still included.

\section{Results}

The purpose of this research project was to find out what cleaning and sanitizing methods are most frequently used in restaurant kitchens and why these methods are used. The type of data gathered was strictly nominal. Descriptive statistics and inferential statistics (chi-square) were used to analyze the data.

\section{Descriptive Statistics}

Descriptive statistics were analyzed using features provided on the Survey Monkey website and excel. The results of the descriptive statistics are presented in the following tables and graphs. 
Figure 1 (below) illustrates the responses to the question: "Have you taken Foodsafe Level 1?" Of the twenty-three respondents, eighteen had taken Foodsafe Level 1 and five had not.

\section{Figure 1. Foodsafe Level 1}

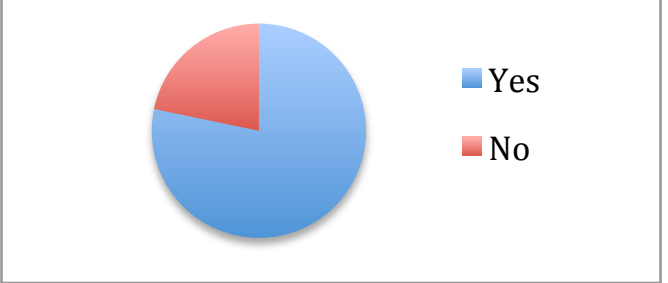

The following chart (Figure 2) depicts which cleaning compounds are most often used to clean countertops in the respondents' place of employment.

\section{Figure 2. Cleaning Compounds}

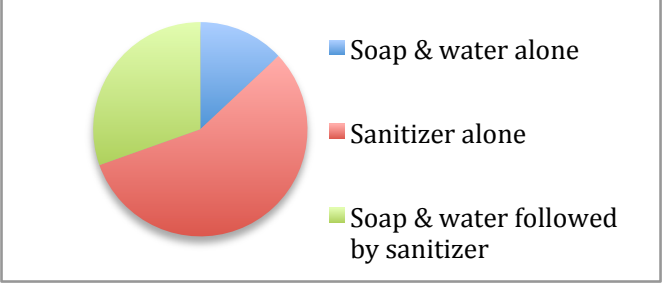

Table 2 (below) shows why the respondents who most often used sanitizer to clean work surfaces (countertops) chose to do so.

\begin{tabular}{|l|l|}
\hline \multicolumn{2}{|l|}{ Table 2. Why is Sanitizer Used? } \\
\hline Company policy & $46.2 \%$ \\
\hline Most effective & $7.7 \%$ \\
\hline $\begin{array}{l}\text { Time savings (as opposed to using soap } \\
\text { and sanitizer) }\end{array}$ & $23.1 \%$ \\
\hline $\begin{array}{l}\text { EHO (Health Inspector) recommended } \\
\text { sanitizer use }\end{array}$ & $15.4 \%$ \\
\hline Other (please specify) & $7.7 \%$ \\
\hline $\begin{array}{l}\text { Other: } \\
\text { People are unaware. They think the sanitizer is "like" } \\
\text { soap }\end{array}$ \\
\hline
\end{tabular}

Of the respondents who selected "sanitizer alone" as the most frequently used cleaning method, Figure 4 (below) depicts how the sanitizer is most often applied.

\section{Figure 3. Sanitizer Application}

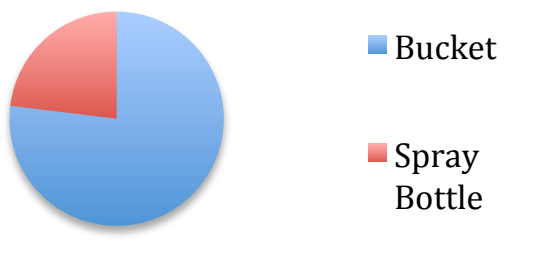

Of the respondents who indicated that sanitizer was applied from a bucket, Table 3 indicates how often the sanitizer in that

bucket was changed.

Table 3. Sanitizer Bucket Replacement Times

\begin{tabular}{|l|l|}
\hline Less than every $\mathbf{2}$ hours & $50.0 \%$ \\
\hline Between $\mathbf{2}$ and $\mathbf{4}$ hours & $20.0 \%$ \\
\hline Between $\mathbf{4}$ and $\mathbf{6}$ hours & $0.0 \%$ \\
\hline Between $\mathbf{6}$ and $\mathbf{8}$ hours & $20.0 \%$ \\
\hline More than every $\mathbf{8}$ hours & $10.0 \%$ \\
\hline
\end{tabular}

Of all the respondents who selected "sanitizer alone" as the most frequently used cleaning method, Table 4 (below) indicates the typical contact time.

\begin{tabular}{|l|l|}
\hline \multicolumn{2}{|l|}{ Table 4. Sanitizer Contact Time } \\
\hline 0-30 seconds & $54.5 \%$ \\
\hline 31 seconds to 1 minute & $18.2 \%$ \\
\hline 1-2 minutes & $0.0 \%$ \\
\hline Over 2 minutes & $0.0 \%$ \\
\hline Until it dries (not wiped off) & $27.3 \%$ \\
\hline
\end{tabular}

Figure 5 (below) depicts the responses to the following scenario question. "You have just sliced chicken on a cutting board using a knife. The knife and cutting board are taken to the dish area to be cleaned. Next you are going to use the same work area to prep ready-to-eat food such as vegetables for salad. How would you clean the countertop between these jobs?"

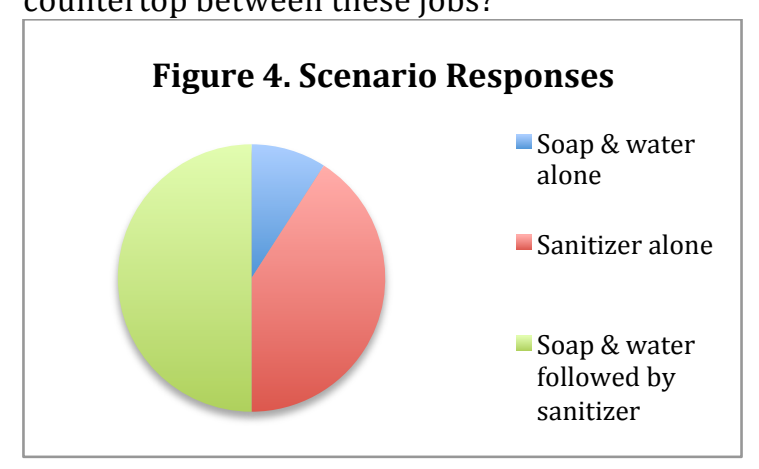

\section{Inferential Statistics}

Chi-square tests were used to compare restaurant type (chain/independent/other), position in the kitchen (management/cook/dishwasher), and Foodsafe to cleaning compounds used. When comparing restaurant type and cleaning compounds used, the p-value was found to be 0.182 and therefore there was no association between restaurant type and cleaning compounds used.

When position in the kitchen and cleaning compounds used, the p-value was found to be 0.453 and therefore there was no association position in the kitchen and cleaning compounds used When comparing Foodsafe Level 1 and cleaning compounds 
used, the p-value was found to be 0.431 and therefore it can be concluded that there is no association successful completion of Foodsafe Level 1 and cleaning compounds used.

\section{Discussion}

Overall, the cleaning compound that respondents reported as being used most often to clean countertops was sanitizer solution only (56.5\%). $30.4 \%$ of respondents indicated they would use soap \& water followed by sanitizer and $13.0 \%$ said they would use soap \& water only. Although the sample size was small, this is troubling because previous studies have indicated that using sanitizer alone is the least effective method when compared to detergent alone or the detergent-rinsesanitize method. In the studies that compared detergent-rinse-sanitize (DRS) to detergent alone or sanitizer alone, DRS was found to be the most effective, most of the time. $(12,14-18)$. In the studies that compared detergent alone to sanitizer alone, detergent alone was always more effective. $(2,13,14,19)$

When asked why sanitizer alone was used to clean countertops, the responses were varied. Most respondents said it was company policy (46.2\%) and the second most likely response was time savings (23.1\%). Some respondents (15.4\%) indicated that an EHO had recommended sanitizer use and that is what lead to sanitizer alone being used to clean countertops. One respondent selected "other" and indicated the reason sanitizer alone was used was that "People are unaware. They think the sanitizer is like soap." It is the speculation of the researcher that it could the policy of certain restaurants or health authorities that a sanitizer bucket/bottle be kept by each station. Then when it is time to clean, the cook/chef may be likely to just reach for the easily accessible sanitizer rather than go to get soap and water. These findings are consistent with a 1984 study by Tebbutt. He found that in practice, use of disinfectants could lead to a false sense of safety. (13) Staff may believe that the disinfectant can reduce or eliminate the need to use detergent and water. (13) Staff may also not be trained on proper concentration and contact time leading to ineffective use.
If the sanitizer was kept in a bucket, most respondents (90\%) indicated that the bucket was changed and replaced with fresh solution more often than every 4 hours. This is good practice because bacteria can also be transferred from one surface to another by cleaning cloths themselves. (13) Only one respondent indicated that the solution was not usually changed for over 8 hours at a time.

When asked about contact time, the majority of respondents $(54.5 \%)$ said that after applying sanitizer it was wiped off within 0-30 seconds. This is insufficient contact time for sanitizer on a cleaned or dirty surface. The contact time for most sanitizing solutions according to the FDA Food Code is a minimum of 30 seconds (8). Some respondents indicated that sanitizer was left on for 30 seconds to 1 minute before being wiped off. This would be sufficient contact time if the surface had been previously washed and rinsed. However these respondents were the ones that indicated only sanitizer was being used to clean. A few respondents indicated that sanitizer was left on the surface until it dried (not wiped off). This is good practice but may still be insufficient if the surface was not previously cleaned. Health Canada does not mention surface cleanliness and requires 10 minutes of contact time for sanitization. (10)

When asked the scenario question that described prepping raw chicken and then a ready to eat food using the same work area, the majority of respondents (50\%) indicated that soap \& water followed by sanitizer solution would be used to clean the countertops. This is higher than the $30.4 \%$ of respondents who said soap \& water followed by sanitizer was used most often to clean countertops. This indicates that approximately half of respondents are aware that soap \& water followed by sanitizer is the most effective method and they are willing to take the extra time and effort in this situation. A significant number of respondents (40.9\%) still indicated that they would still use sanitizer solution only to clean up after this scenario, and the remainder (9.1\%) would use soap \& water only. This is especially troubling because of the potential for cross contamination in this situation. In 1994, (Humphrey, Martin, \& Whitehead) found that Salmonella enteritidis could be found on surfaces up to 
$40 \mathrm{~cm}$ away from a mixing bowl after mixing raw eggs and could be recovered up to 24 hours after contamination. (3)

The majority of respondents have taken Foodsafe Level 1 (78.3\%). It was found that there was no association between having taken Foodsafe Level 1 and cleaning compounds used. This could indicate that there is not enough emphasis in the Foodsafe Level 1 course on proper cleaning and sanitizing steps.

Although using detergent alone was found to be more effective than using sanitizer alone in multiple studies $(2,13,14,19)$, and more effective than detergent-rinse-sanitize in one study (13), this survey found that only $13 \%$ of respondents most often used soap \& water alone to clean countertops. When asked why they chose this method, company policy and time-saving were cited, as well as one respondent who indicated "Time saving and because the food is heavily plant based. Every time meat is prepped sanitizer is used. Hot soap and water in between other jobs." This response seems like the ideal cleaning and sanitization policy for restaurants to have because there is likely not much of a bacterial load on the counter between most jobs and soap \& water can reduce bacterial contamination by 2-3 logs. (12)

In order for sanitizer to be effective, studies have shown that it must be applied on a cleaned and rinsed surface. $(11,12)$. The results of this study indicate that sanitizer alone is frequently being used for cleaning countertops in BC restaurant kitchens. This practice should be changed to prevent cross-contamination that could lead to an outbreak. One solution would be to deemphasize the importance placed on sanitizer. Kitchens are busy places and staff are not likely to take the time to use the detergent-rinse-sanitize method for every cleaning job. Since detergent alone is the second most effective method, soap \& water should be used most of the time and sanitizer should be used only where the potential for cross contamination is the highest.

\section{Recommendations}

Environmental Health Officers should review sanitation plans and talk with operators to determine current cleaning practices in food service establishments.
Operators and staff should be re-educated on the importance of the three-step method. It may be beneficial to recommend that sanitizer use be decreased overall to encourage the use of soap and water. It may be practical to only require sanitizer after high-risk jobs such as preparing raw meat or at the end of the day.

\section{Limitations}

The most significant limitation was the small sample size for this survey. Although 47 responses were initially received, 24 had to be eliminated for various reasons. With more time/money, an in person survey in restaurant kitchens could have been conducted, increasing the response rate and the validity. Another limitation was that the sample reached may not be representative of the entire population of restaurant kitchen staff in BC. The researcher distributed the survey to her Facebook contacts and 14 different people shared it. However, there was no second round of sharing (snowball effect) and there is a possibility that some of the respondents worked in the same restaurant. With more time, the Facebook link could have been left open longer and other methods to encourage sharing and responses could have been looked at such as restaurant industry groups or Linkedin.

\section{Future Research}

A microbiological study would be useful, directly comparing the effectiveness of using soap \& water alone to sanitizer alone to soap \& water followed by sanitizer on countertops. This study could also be repeated, possibly taking place in person at restaurants to elicit a higher response rate.

\section{Conclusions}

Cross contamination can take place in restaurants and lead to an outbreak. The regulations requiring a detergent-rinsesanitize cleaning method are supported by scientific evidence that this removes the most bacterial contamination when done correctly. In practice, some restaurant staff do not use sanitizer effectively and may believe it is a substitute for detergent. Using sanitizer alone is not as effective as using detergent alone. If staff are busy and are only going to use one cleaning step, soap \& water alone is the best method. Sanitizer may not be required for every cleaning job but should be used when the potential for cross contamination is high. Further studies 
that look specifically at the potential for cross contamination via food contact surfaces cleaned with detergent alone compared to sanitizer alone would be beneficial.

\section{Acknowledgements}

The authors wish to thank the Environmental Health department at the British Columbia Institute of Technology for supporting their research.

\section{References}

(1) Thomas MK, Murray R, Flockhart L, Pintar K, Fazil A, Nesbitt A, et al. Estimates of Foodborne Illness-Related Hospitalizations and Deaths in Canada for 30 Specified Pathogens and Unspecified Agents. Foodborne Pathog Dis [Internet]. 2015 Oct [cited 2016 Oct 24];12(10):820-7. Available from: http://online.liebertpub.com/doi/10.1089/ fpd.2015.1966

(2) Gkana E, Lianou A, Nychas G-Je. Transfer of Salmonella enterica Serovar Typhimurium from Beef to Tomato through Kitchen Equipment and the Efficacy of Intermediate Decontamination Procedures. J Food Prot [Internet]. $2016 \mathrm{Jul}$;9(7):1252- 8. Available from: http://10.0.16.219/0362- 028X.JFP-15531

(3) Humphrey TJ, Martin KW, Whitehead A. Contamination of hands and work surfaces with Salmonella enteritidis PT4 during the preparation of egg dishes. Epidemiol Infect [Internet]. 1994 Jan 1;113(3):403-9. Available from: http://0-

search.ebscohost.com.innopac.lib.bcit.ca/log in. $\operatorname{aspx}$ ?direct=true $\& \mathrm{db}=\mathrm{ffh} \& \mathrm{AN}=1995-03-\mathrm{Q}-$ 0003

(4) Bang J, Hong A, Kim H, Beuchat LR, Rhee MS, Kim Y, et al. Inactivation of Escherichia coli O157:H7 in biofilm on food-contact surfaces by sequential treatments of aqueous chlorine dioxide and drying. Int J Food Microbiol [Internet]. 2014 Nov 17;191:129_ 34. Available from: http://10.0.3.248/j.ijfoodmicro.2014.09.014

(5) Food Premises Regulation [Internet]. 210/99 2016. Available from: http://www.bclaws.ca/EPLibraries/bclaws_ new/document/ID/freeside/11_210_99\#se ction 16

(6) Canadian Food Inspection System, Implementation Group. Food Retail and Food Services Code [Internet]. 2004 p. 76. Available from:

http://foodsafe.ca/resources/Food_Service s_Code2004.pdf

(7) Marriott NG, Gravani RB. Principles of food sanitation. [Internet]. Principles of food sanitation. PO Box 14302, 14197 Berlin, Germany; Springer. Tel. +496221 4870 . www.springer.com. Price GBP 44.00.; 2006. 425 p. Available from: http://0search.ebscohost.com.innopac.lib.bcit.ca/log in .asp $x$ ?direct $=$ true $\& d b=$ ffh $\& A N=2006-06-$ Cb1046

(8) Food and Drug Administration. Food Code [Internet]. 2013 [cited 2017 Mar 17]. Available from:

https://www.fda.gov/downloads/Food/Gui danceRegulation/RetailFoodProtection/Foo dCode/UCM374510.pdf

(9) Government of Canada, Health Canada, Health Products and Food Branch NHPD. Guidance Document: Safety and efficacy requirements for hard surface disinfectant drugs [Internet]. 2014. Available from: http://www.hc-

sc.gc.ca/dhpmps/prodpharma/applicdemande/guideld/disinfect-desinfect/hsddddsdeng.php\#a217

(10) Government of Canada, Health Canada, Health Products and Food Branch N and NHPD. Hard Surface Disinfectants Monograph- Revised. 2015.

(11)Lee J, Cartwright R, Grueser T, Pascall MA. Efficiency of manual dishwashing conditions on bacterial survival on eating utensils. J Food Eng [Internet]. 2007 Jun;80(3):885-91. Available from: http://10.0.3.248/j.jfoodeng.2006.08.003

(12) Gaulin C, Lê M-L, Shum M, Fong D. Disinfectants and sanitizers for use on food contact surfaces [Internet]. Vancouver; 2011 [cited 2016 Oct 21]. Available from: http://www.ncceh.ca/sites/default/files/Fo od_Contact_Surface_Sanitizers_Aug_2011.pd $\mathrm{f}$

(13) Tebbutt GM. A microbiological study of various food premises with an assessment of cleaning and disinfection practices. J Hyg (Lond) [Internet]. 1984 Oct;93(2):365-75. Available from: http://0search.ebscohost.com.innopac.lib.bcit.ca/log in $. a s p x ? d i r e c t=$ true $\& d b=m n h \& A N=6438230$ 
(14) Gilbert RJ. Comparison of materials used for cleaning equipment in retail food premises, and of two methods for the enumeration of bacteria on cleaned equipment and work surfaces. J Hyg (Lond) [Internet]. 1970 Jun;68(2):221-32. Available from: http://0search.ebscohost.com.innopac.lib.bcit.ca/log in.aspx ?direct $=$ true $\& d b=m n h \& A N=4914087$

(15) Hall A, Saltmarsh M, Fielding L, Peters A. Evaluation of three commonly used cleaning methods for reducing bacterial numbers on hot drinks vending machine mixing bowls artificially contaminated with Bacillus cereus and Staphylococcus aureus. J Foodserv [Internet]. 2007 Aug;18(4):153. Available from: http://10.0.4.87/j.17454506.2007.00061.x

(16) Gibson H, Taylor JH, Hall KE, Holah JT. Effectiveness of cleaning techniques used in the food industry in terms of the removal of bacterial biofilms. J Appl Microbiol [Internet]. 1999 Jul;87(1):41-8. Available from: http://0search.ebscohost.com.innopac.lib.bcit.ca/log in. $\operatorname{aspx}$ ?direct $=$ true $\& \mathrm{db}=\mathrm{mnh} \& \mathrm{AN}=10432586$

(17) Røssvoll E, Langsrud S, Bloomfield S, Moen B, Heir E, Møretrø T. The effects of different hygiene procedures in reducing bacterial contamination in a model domestic kitchen. J Appl Microbiol [Internet]. 2015 Aug;119(2):582-93. Available from: http://10.0.4.87/jam.12869

(18) Soares VM, Pereira JG, Viana C, Izidoro TB, Bersot L dos S, Pinto JP de AN. Transfer of Salmonella Enteritidis to four types of surfaces after cleaning procedures and crosscontamination to tomatoes. Food Microbiol [Internet]. 2012 Jun;30(2):453-6. Available from: http://10.0.3.248/j.fm.2011.12.028

(19) NSF International. REPORT ON BACTERIOLOGICAL SWAB TESTS [Internet]. Ann Arbor; 1992 [cited 2016 Oct 19]. Available from: http://www.hitm.com/Documents2008/NSFHobart-PMIdishwasher.pdf

(20) Ravishankar S, Zhu L, Jaroni D. Assessing the cross contamination and transfer rates of Salmonella enterica from chicken to lettuce under different foodhandling scenarios. Food Microbiol [Internet]. 2010

Sep;27(6):791-4. Available from: http://10.0.3.248/j.fm.2010.04.011
(21) Welcome to SurveyMonkey! [Internet]. [cited 2016 Nov 21]. Available from: https://www.surveymonkey.com/home/ 